\title{
La larga marcha hacia la libertad La evolución ideológica de Octavio Paz
}

\author{
JUAN ARANA \\ Universidad de Sevilla
}

\begin{abstract}
Octavio Paz se vio inmerso a lo largo de su vida en los acontecimientos más significativos del siglo XX. Este contacto directo con la historia le llevó a cuestionar repetidas veces los principios básicos de la acción política y los valores que deben sustentarla. En este trabajo se analizan las diversas fases de la evolución ideológica de Paz, que no estuvo subordinada a las urgencias de una ambición personal, lo que le permitió zafarse del oportunismo de tan-
\end{abstract}

\begin{abstract}
tos intelectuales latinoamericanos. En lugar de ir a remolque de los tiempos, sus reflexiones responden a la lógica de un desarrollo interno, que profundiza progresivamente en el alcance y las consecuencias de la idea de libertad, una libertad que es concebida lejos del limbo de las abstracciones y se piensa cada vez más en función de las exigencias irrenunciables del hombre de carne y hueso.
\end{abstract}

A lo largo del siglo XX han ocurrido muchas cosas y, si todavía es pronto para pronosticar cómo será valorada esta centuria por los historiadores que en el futuro se ocupen de ella, ya se puede augurar que no la presentarán como una época tranquila y rutinaria. La aceleración de la historia ha arrollado literalmente a sus protagonistas, de manera que éstos se han vuelto viejos antes de que por su edad les correspondiera el retiro. En el caso de los artistas e intelectuales, la consigna de "renovarse o morir» se ha convertido en imperativo categórico, aunque ello les forzara a experimentar evoluciones accidentadas e incluso caóticas, más comprensibles y mejor aceptadas por la sociedad en el caso de los primeros que en el de los segundos. Nada, en efecto, hay que oponer a que un pintor o un músico cambie de lenguaje o de temática al hilo de unos tiempos que corren raudos y tempestuosos. En cambio, todavía hoy se aprecia en quien ejerce el oficio de pensar que sea fiel a sí mismo y a lo que en un momento sostuvo, aunque fuera decenios atrás. Naturalmente, a nadie se le prohíbe evolucionar, pero nos gusta que la evolución de quienes trabajan con las ideas tenga una lógica y sea explicable, descartando la sospecha de que han convertido su trabajo en un juego frivolo y descomprometido. Dicho con otras palabras, desconfiamos de los que sin más ni más se apuntan a la última corriente en boga en el campo de la filosofía, la política o las ciencias humanas, porque pensamos que quien ajusta a la moda sus convicciones 
en realidad carece de criterio. Es como si no nos resignásemos a que los temas de que se ocupa el intelecto queden total e irreversiblemente inmersos en el tiempo, a pesar de los esfuerzos realizados en tal sentido por las corrientes postmodernas.

En lo que atañe más concretamente al pensamiento político, los que nacieron en la primera mitad del siglo y han conseguido sobrevivir hasta la última parte de la segunda han asistido a un inesperado giro de los "vientos de la historia» que soplaron primero intensamente en favor del socialismo y luego rolaron en la dirección que preconizan las opciones liberales. No voy a discutir si este cambio de signo es provisional o definitivo, ni tampoco si se puede explicar, demostrar e incluso archidemostrar que era inevitable. Me basta con señalar que la mudanza ha puesto en serios apuros a los intelectuales que se han atenido a sus propios principios y pronósticos. Cierto es que muchos adaptan a los avatares históricos aquel consejo que daba Quevedo a los que deseaban ser seguidos por las mujeres: "caminar delante de ellas», y que una buena parte lo hace incluso con ingenio y habilidad. Pero es muy escaso el número de los que, siendo fieles a sí mismos y, sobre todo, a una genuina vocación ética y política, han anticipado las transformaciones y las han sabido inspirar y propiciar con mayor o menor eficacia. Karl Popper es sin duda uno de estos pocos privilegiados y se ha ganado un puesto en la historia de las ideas políticas por haber escrito La sociedad abierta y sus enemigos cuando y como lo hizo. En el ámbito cultural hispanohablante, Octavio Paz representa un caso igualmente notorio. Paz adoptó un compromiso ideológico muy claro con el socialismo en los años treinta, pero pronto rompió con la esclerosis de la analítica marxista al uso y con las simplificaciones de los revolucionarios de izquierda en todo el mundo, adoptando una gallarda postura de defensa de la libertad a todos los niveles que le valió primero la hostilidad, ${ }^{1}$ luego el respeto y por último la rendida admiración de muchos contemporáneos.

El propósito que persigo con este trabajo no es adoptar un tono hagiográfico ni tampoco una pose desmitificadora en la valoración de la evolución ideológica de Octavio Paz. Me propongo simplemente recapitular los hechos básicos que la jalonan e indagar si existe o no una lógica y una razón profunda de ser en la misma. Advertiré, sin embargo, que no considero en sí mismo un mérito especial el hecho de cambiar de filiación política. Sólo significa que el hombre en cuestión será considerado traidor por unos y converso por otros. Será difícil considerarlo un dogmático, pero levantará sospechas de oportunismo. No obstante la evolución desde la izquierda hacia la derecha de algunos intelectuales y artistas contemporáneos suele gozar a priori de una cierta aureola de prestigio precisamente en ciertos sectores de la derecha. Esto me parece sorprendente porque supone un reconocimiento implícito de que lo natural en un intelectual o en un artista es profesar una ideología de izquierda, lo cual no tendría

\footnotetext{
${ }^{1}$ Reflejada en múltiples artículos de prensa con títulos semejantes a éste: «Su ideología fue
} de izquierda, luego de centro y ahora nada», Enrique Fallie Fuentes, El Heraldo de México, 25.2.1984. 
que ser así para quien defiende la ideología opuesta, a no ser que padezca un soterrado sentimiento de inferioridad o una mala conciencia que debe ser lavada. En resumidas cuentas, ocurre como si algunos liberales pensasen que a ellos también les hubiera gustado militar en el socialismo, y que no lo han hecho por falta de fe, por realismo o por otros motivos menos confesables. Por eso reciben con los brazos abiertos a los hijos pródigos que retornan a la casa paterna después de haber vivido su sueño revolucionario: suavizan sus remordimientos y confirman empíricamente lo acertado de su elección. Por lo que a mí respecta, me tienen sin cuidado los entresijos psicoanalíticos de estas actitudes y propongo adoptar un talante completamente neutro respecto al fenómeno, reservando las valoraciones para después de haber concluido el análisis.

La primera pregunta que suscita un proceso evolutivo es saber si se trata de algo continuo o discontinuo: ¿hay una ruptura, una quiebra en la trayectoria de quien al principio abrigaba unas convicciones y finalmente desembocó en otras muy diferentes? Es muy raro que a lo largo de una biografía no existan momentos de hondo significado que hayan supuesto al menos una inflexión pronunciada en el rumbo seguido. Octavio $\mathrm{Paz}$ los ha tenido, indudablemente, y quizás por ello haya considerado en alguna ocasión su vida dividida en dos partes encontradas:

"Y ahora que mis manos sangran y mis dientes tiemblan, inseguros, en una cavidad rajada por la sed y el polvo, me detengo y contemplo mi obra: he pasado la segunda parte de mi vida rompiendo las piedras, perforando las murallas, taladrando las puertas y apartando los obstáculos que interpuse entre la luz y yo durante la primera parte de mi vida.» ${ }^{2}$

El biógrafo Fernando Vizcaíno opone también su juventud de izquierdas a una madurez consagrada a la crítica del socialismo y sus mitos. ${ }^{3}$ Pero la escisión en este caso no es algo que se deje confinar en el esquema lineal del « antes» y el « después». La tensión dialéctica entre elementos contrapuestos está en todos y cada uno de los momentos de su existencia y, en lo que atañe a la política, se remonta incluso a su árbol genealógico: el abuelo Ireneo $\mathrm{Paz}^{4}$ fue un liberal aliado con los porfiristas, mientras que el padre, Octavio $\mathrm{Paz}$ Solórzano, militó en las filas de líder campesino revolucionario Emiliano Zapata. Se puede decir que sus antecesores habían sembrado en él una doble semilla que germinó dando frutos que dividieron su vida y su mente: « mi abuelo tenía razón, pero también era cierto lo que decía mi padre». ${ }^{5}$

\footnotetext{
${ }^{2}$ "Trabajos del poeta» en: Libertad bajo palabra, Poemas (1935-1975), Barcelona, Seix Barral, 1981, p. 176

${ }^{3}$ Véase Fernando Vizcaíno, Biografia politica de Octavio Paz, Málaga, Algazara, 1993, p. 72.

${ }^{4}$ Nombre poco acorde con el temperamento de este belicoso liberal de vieja escuela, que llegó a matar en duelo a un adversario político.

${ }^{5}$ Declaración de O. Paz a Julio Scherer García, «Octavio Paz», Proceso, 57, 1977, p. 610.
} 
No sería justo, sin embargo, achacar al poeta una especie de esquizofrenia ideológica; por el contrario: la escisión es en este caso algo asumido como inevitable, dada la condición de nuestro siglo, e incluso encierra, a ojos del poeta, posibilidades de ser transformada en un camino de liberación:

"En el siglo XX la escisión se convirtió en una condición connatural: éramos realmente almas divididas en un mundo dividido. Sin embargo, algunos pensábamos transformar esa hendidura psíquica en independencia intelectual y moral. La escisión nos salvó de ser devorados por el fanatismo monomaníaco de muchos de nuestros contemporáneos.» ${ }^{6}$

El propio Paz ha destacado la contraposición existente en los años 30 entre sus ideas políticas y sus convicciones estéticas y poéticas. Por aquel entonces se entabló en México una polémica entre los partidarios de la educación socialista y los defensores de la libertad de cátedra. Paz optó por la educación socialista y en general adoptó posturas propagandísticas de izquierda, como la que le llevó a apoyar la idea del arte comprometido, "al servicio de la idea marxista, integrado por jóvenes artistas rusos y alemanes poseídos de la verdad». ${ }^{7}$ Años más tarde volcaría en cambio todas sus energías en la defensa de la libertad e independencia del quehacer artístico, lo que, por ejemplo, le haría atacar con energía a Neruda por su instrumentalización de la literatura. ${ }^{8}$ No obstante, antes de ser formulado teóricamente, habitaba en $\mathrm{Paz}$ el anhelo de romper con todas las servidumbres que puedan mediatizar la escritura: si el encendido poema ;No pasarán! (1936) exalta los valores revolucionarios, la colección Raíz del hombre publicada poco después (1937) es un canto al amor, a las vivencias personales e irrepetibles que sólo pueden comunicarse a través del arte puro. Así, todos han tenido desde el principio instrumentos para «salvar» y también para «condenar» a Octavio Paz. Más tarde, cuando en 1959 sus escritos fueron traducidos al francés, la crítica también encontró un doble asidero, de manera que la revista radical Lettres françaises pudo alabar el experimentalismo de la poesía contenida en Aigle ou soleil?, al tiempo que censuraba el mensaje politico del Labyrinthe de la solitude. ${ }^{9}$ Aunque en tiempos más recientes la consagración definitiva del escritor haya velado un poco las críticas, no creo que la dualidad haya desaparecido, sino tan sólo que existe un interés general por "recuperar» a Paz, aunque, por supuesto, cada cual recupera al Paz más acorde con su propio interés.

Se ha señalado que la escisión característica de la obra literaria de Paz también se encuentra en otras esferas de su actividad, por ejemplo, en la ambiyalencia de sus relaciones con el poder establecido, que combinan proximidad

\footnotetext{
${ }^{6}$ O. Paz, Itinerario, México, F.C.E., 1993, p. 51.

7 O. Paz, «Ética del artista», en Barandal, 1931, núm. 5, pp. 1-5. Citado por Vizcaíno, Biografía..., p. 59 .

${ }^{8}$ Véase O. Paz, «Respuesta a un cónsul», en Letras de México, 15.8.1943, p. 5.

9 Véase Vizcaíno, Biografía..., p. 105.
} 
y lejanía, colaboración y ruptura, aliento y censura... Su separación de los comunistas estuvo llena de alternativas y no le impidió, a pesar de sus íntimas dudas, intentar alistarse durante la guerra civil española en el ejército republicano como comisario político. ${ }^{10}$ Del mismo modo, supo compatibilizar sus lúcidos diagnósticos de los males del sistema político mexicano con el leal servicio a sus gobiernos por más de 20 años. Estas connivencias no fueron óbice para que en su momento elevase la voz con contundencia para discrepar, sin que aparentemente le importaran mucho las consecuencias de tales gestos: la publicación en Sur del informe sobre el proceso Rousset (1951), que aireaba la existencia de campos de concentración y exterminio en la Unión Soviética, la sonora dimisión del puesto de embajador de México en la India a raíz de la matanza de Tlatelolco (1968), o la pública desautorización del régimen sandinista en Nicaragua (1984) son algunos de los episodios más conocidos de esta cara controvertida del Paz otrora acusado de complaciente. A pesar de ser un diplomático profesional, no parece que se haya dejado aconsejar por la prudencia política en los momentos estelares de su carrera. La heterodoxia (en el sentido menos trivial de la palabra) constituye una de las fibras más profundas de su carácter, tal como expresa en los versos que escribió tras visitar la tumba de un antiguo heresiarca:

"Ante el patriarca nestoriano

latió más fuerte mi corazón herético.» ${ }^{11}$

Tratemos no obstante de profundizar un poco en el trasfondo de todos estos vaivenes. Por lo dicho hasta ahora queda claro que Octavio Paz abrigó en su juventud las ilusiones que la izquierda radical inspiró en tantos corazones de la época y que más tarde fue construyendo en solitario una actitud mucho más independiente, en la que los valores de la democracia sin apellidos adquirieron un papel cada vez más determinante. Si hubo una "conversión» o un "desengaño» los indicios apuntan a la fecha de 1939, en la que los poderes autocráticos concertaron una alianza por encima de sus discrepancias ideológicas. Ese mismo año Paz publica un ensayo, Americanidad de España, en el que rompe los moldes de la ortodoxia marxista y rescata la noción de « democracia» de la superestructura ideológica del estado burgués, haciéndola más universal y originaria que la de " socialismo»:

«La democracia es una idea universal, un hecho mundial. No pertenece, tan solo, a franceses e ingleses, y no es tampoco expresión de la burguesía revolucionaria del XVIII y XIX. Es también la meta final del socialismo (...) La defensa de la democracia es cuestión de vida o muerte. ¡Luchemos en el Frente Americano por la victoria del Pueblo Español! $»^{12}$

${ }^{10}$ Véase O. Paz, Itinerario, p. 67.

11 O. Paz, Ladera Este, en Poemas, p. 415.

12 O. Paz, "La Americanidad de España», 1939, citado por Vizcaíno, Biografia..., p. 72. 
Y es que una de las claves del pensamiento de Paz consiste precisamente en el esfuerzo universalizador. ${ }^{13} \mathrm{Su}$ indagación progresa siempre de lo particular a lo general, no como términos diametral y mecánicamente opuestos, sino orgánicamente entrelazados. En este sentido se puede decir que el socialismo se le quedó demasiado pequeño, por cuanto que no dejaba de ser un modo particular, confinado en una etapa histórica singular y pasajera, de la lucha permanente del hombre por el logro de la libertad y la justicia. La democracia en cambio, aunque fuese introducida por una clase social concreta en un momento histórico determinado (la naciente burguesía a fines del siglo XVIII), tenía una vocación más amplia y universal; podía y debía convertirse en un legado asumible por todas las generaciones que vinieron detrás. Durante los años treinta, el joven Octavio Paz piensa que cabe entender el socialismo como un momento más en este proceso transhistórico, y por eso dice en el último párrafo citado que la democracia constituye la meta final del socialismo. No tardará en desengañarse, al menos por lo que se refiere a las plasmaciones históricas concretas del socialismo, tal como era entendido y practicado por los partidos comunistas de todo el mundo.

Un punto de coincidencia del marxismo con la filosofía de Octavio Paz es la concepción dialéctica del hombre y la historia. Pero el acuerdo es más aparente que real, porque ya vimos que la visión escindida de las cosas tiene en el caso del poeta unas raíces muy hondas, constituye una herencia y una metafísica que es previa a cualquier doctrina o ideología que pudiera conocer a lo largo de su vida. Además, hay una diferencia notoria entre la dialéctica hegeliano- marxista y la paziana: mientras aquélla desencadena un proceso lineal de progreso y está integrada por momentos que van siendo superados a medida que las contradicciones se resuelven en negaciones dobles que asumen y superan lo negado, en Paz la contraposición forma la estructura misma del ser y del devenir, produce vida más que progreso. La tensión de los contrarios no es superable en una reconciliación final, pues forma un momento estructuralmente necesario y hasta deseable si se quiere obtener resultados valiosos. Para el autor mexicano, el dualismo es inherente a toda sociedad, al igual que la aspiración a superarlo: se crea así una dialéctica de la soledad que es la condición de posibilidad del amor. Pero la sociedad moderna tiende a negar las contradicciones mediante la uniformización, suprimiendo tal dialéctica y desembocando en el empobrecimiento y marasmo consiguiente. ${ }^{14}$

Por otro lado, Paz nunca comulgó con la visión unilateralmente dialéctica de la contraposición clasista entre la burguesía y el proletariado. Las discrepancias entre las previsiones teóricas de Marx y Engels y la marcha de los procesos revolucionarios que trataron de realizarlas no pasaron desapercibidas a sus ojos ni fueron disimuladas por su pluma, frente al ciego fideísmo

\footnotetext{
${ }^{13}$ Véase Ricardo Gullón, «El universalismo de Octavio Paz», en: Octavio Paz, ed. de P. Gimferrer, Madrid, Taurus, 1982, pp. 223-235.

${ }_{14}$ Véase O. Paz, El laberinto de la soledad, México, F.C.E., 1982, p. 181.
} 
de tantos intelectuales de izquierda. Otra vez se le quedaba demasiado pequeño el esquema doctrinal de los ideólogos contemporáneos. El distanciamiento de los comunistas mexicanos, el contacto con los exiliados españoles y franceses durante la segunda guerra mundial, la experiencia estadounidense y los dorados años en el París de la posguerra fueron enriqueciendo y madurando un pensamiento cada vez más complejo. Con particular nostalgia será evocada más tarde la etapa parisina:

"Me unian a mis amigos afinidades artísticas e intelectuales. Vivía inmerso en la vida literaria de aquellos días, mezclada a ruidosos debates filosóficos y políticos. Pero mi secreta idea fija era la poesía: escribirla, pensarla, vivirla. Agitado por muchos pensamientos, emociones y sentimientos contrarios, vivía tan intensamente cada momento que nunca se me ocurrió que aquel género de vida pudiera cambiar.» ${ }^{15}$

En el cultivador de la poesía confluyen y entran en conflicto como en ningún otro la vocación del artista y la del intelectual: expresión y contenido, verdad y belleza, compromiso y distancia crítica, despego lúcido y fusión apasionada forman exigencias que no puede desatender ni tampoco satisfacer simultáneamente. Si el conflicto es creador, nadie como él lo experimenta dolorosamente. Y Octavio Paz lo demostró precisamente en aquel momento escribiendo El laberinto de la soledad, cuya primera edición apareció en 1950, aunque los primeros esbozos de su redacción se remontan a siete años antes. A mi juicio uno de los méritos más destacados de este libro es que, partiendo de una reflexión sobre una cultura y una época muy determinada, la del México contemporáneo, sabe atisbar problemas que trascienden ampliamente dichos límites. Una vez más el esfuerzo universalizador como signo de identidad del estilo intelectual de Paz; más aún: si El laberinto de la soledad consigue hablarnos a todos nosotros de nuestra propia soledad, se debe a que quien lo escribió supo profundizar en las raíces de la suya. La universalidad no se da, en efecto, en la estratosfera de las abstracciones vacías de contenido, sino en lo hondo de cada individuo, en lo eterno de cada instante, en las claves escondidas de cada coyuntura histórica. Para ser un personaje cosmopolita y abierto a todas las culturas, Octavio Paz está singularmente arraigado en la suya; por eso puede interesar a los que tienen otra. Así, el primer reproche que formula en este libro contra el capitalismo no se expresa en términos de injusticia y explotación, sino en los de pérdida de identidad y despersonalización:

" El obrero moderno carece de individualidad. La clase es más fuerte que el individuo y la persona se disuelve en lo genérico. Porque ésta es la primera y más grave mutilación que sufre el hombre al convertirse en asalariado industrial. El capitalismo lo despoja de su naturaleza humana - lo que no ocurrió con el siervo- puesto que reduce todo su ser a fuerza de trabajo, transformándolo por este solo hecho en objeto.» ${ }^{16}$

${ }^{15}$ O. Paz, Vislumbres de la India, Barcelona, Seix Barral, 1995, p. 6.

${ }^{16}$ O. Paz, El laberinto..., p. 61. 
Desde el punto de vista ideológico, El laberinto de la soledad retiene la descalificación del sistema de la economía de mercado, pero no tanto por su presunta ineficacia para resolver los problemas sociales, sino más bien por el empobrecimiento con que lo hace: la sociedad tecnocrática aparece como la máquina perfecta donde el movimiento se convierte en inmovilidad, esto es, en movimiento sin fin. ${ }^{17}$ Las cosas marchan, y cada vez de un modo más frenético y acelerado, pero sin un destino, sin un sentido que plenifique, organice y convierta en "vivo» un proceso que degenera en mera reiteración mecánica, sinónimo del estancamiento. Este tipo de ataque no era inusual entre los críticos izquierdistas del capitalismo, pero en Paz no se trata de una mera consigna ni de una confrontación especulativa de las duras aristas de la realidad presente con las lejanas perfecciones de la utopía soñada. El término de comparación es en este caso un pasado tan real y tan imperfecto como el hoy: a pesar de lo que cabe decir en su contra, la vieja sociedad colonial introducida por los españoles en el Nuevo Mundo carecía de muchos de los defectos que ha importado el liberalismo capitalista: en ella todos tenían un lugar, un sentido, una justificación. Por supuesto, esta sorprendente reivindicación de una herencia que muchos intelectuales mexicanos de la época preferian exorcizar no tiene nada que ver con el tradicionalismo melancólico: «No pretendo justificar la sociedad colonial. En rigor, mientras subsista esta o aquella forma de opresión, ninguna sociedad se justifica. Aspiro a comprenderla como totalidad viva y, por eso, contradictoria. ${ }^{18}$ Lo malo del sistema liberal sería precisamente haber querido limar en nombre de una racionalidad anónima todas esas contradicciones necesarias a la vida. Pero, ¿cómo y por qué? Paz acredita su interpretación no por medio de silogismos descarnados, sino mediante una reflexión crítica acerca de la evolución de su propio país tras la independencia.

Apoyarse en la realidad de una sociedad relativamente marginal como la mexicana encierra sin duda el riesgo de quedar clausurado en la descripción de particularismos anecdóticos, pero por otro lado ofrece la posibilidad de desmontar el valor de los tópicos al uso que sólo valen para unos pocos casos y momentos presuntamente "centrales». Así, Paz observa que la dialéctica amo- esclavo no carece de excepciones: en el caso mexicano, toda la sociedad participa del sentimiento de inferioridad. ${ }^{19}$ Este primer indicio apunta a una tesis de amplio calado: la historia es un proceso complejo, mejor dicho, un conjunto de procesos que no se deja reducir a la lógica reduccionista de una contraposición elemental. No hay fórmulas mágicas para resolver los males de una sociedad ni para enseñarle al hombre cómo ha de andar su camino. Este fue el error de los políticos decimonónicos, que engañaban a los ciudadanos o bien se engañaban a sí mismos con planteamientos extemporáneos. Un país que arrastra tras de sí una larga e ininterrumpida serie de fracasos sabe de

\footnotetext{
17 Véase O. Paz, El laberinto..., p. 62.

${ }^{18}$ O. Paz, El laberinto..., p. 94.

19 Véase O. Paz, El laberinto..., p. 65.
} 
esto más que otro que ha tenido la suerte de aprovechar una situación favorable. Pero en México, por una u otra razón, nada acabó de funcionar: a pesar de su anquilosamiento y atraso histórico, la sociedad colonial se aproximó bastante a un cuerpo social vivo y equilibrado, pero ni los que forjaron la independencia del país, ni los que lo reformaron a mitad de siglo, ni tampoco quienes pretendieron encaminarlo más tarde por la senda del progreso consiguieron evitar la marginación creciente de la mayor parte de la población. Las causas del fenómeno son múltiples, pero hay una que retiene la atención de Octavio Paz porque afecta a la relación entre la teoría y la práctica de la política. La menciona a propósito de la función desempeñada por el positivismo como filosofía oficiosa de la dictadura de Porfirio Díaz en México (1876-1911):

"El primitivo, abstracto y revolucionario principio de la igualdad de todos los hombres deja de regir las conciencias, sustituido por la teoría de la lucha por la vida y la supervivencia del más apto. El positivismo ofrece una nueva justificación de las jerarquías sociales. Pero ya no son la sangre, ni la herencia, ni Dios, quienes explican las desigualdades, sino la Ciencia.» ${ }^{20}$

Esto podría sonar a condena del darwinismo social como coartada ética de la injusticia social. Lo es, en efecto, pero también algo más sutil: lo terrible no es que los explotadores empleen cínicamente la religión, la historia o la ciencia para reforzar sus abusos, sino que haya mentes que buscando la verdad y el bien se conviertan inopinadamente en sus cómplices. Esto es indispensable para que lo otro ocurra: al fin y al cabo todo engaño es inofensivo en cuanto la mayoría sabe que lo es. Y la falacia del positivismo, como la del liberalismo burgués, estriba precisamente en que, a su modo, es verdad, es decir, en que puede ser una verdad teórica y a la vez una mentira práctica:

" La Reforma niega la tradición, mas nos ofrece una imagen universal del hombre. El positivismo no nos dio nada. En cambio, mostró en toda su desnudez los principios liberales: hermosas palabras inaplicables.» ${ }^{21}$

No hay nada más peligroso para un político que empeñarse en poner en práctica una teoría hermosa, pero inaplicable. Forzosamente resultará algo distinto del fin perseguido, y además será un efecto perverso. El liberalismo nace como una doctrina que promueve la igualdad de los hombres, tanto como su libertad; sin embargo, su puesta en marcha como eje articulador de la sociedad conduce en muchos casos a incrementar las desigualdades, a yugular la libertad de los individuos e incluso a privarles de la riqueza y dignidad constitutivas del hombre, reduciéndolos a su valor de mercado. Según esto, el criterio pertinente para evaluar una doctrina política no es la « hermosura» de su diseño ni la excelencia del ideal final que propone, sino las consecuencias prácticas

${ }^{20}$ O. Paz, El laberinto..., p. 118.

${ }^{21}$ O. Paz, El laberinto..., p. 120. 
inmediatas de la acción de gobierno inspirada en ella. Si éstas son nefastas, es preferible incluso lanzarse a ciegas a la lucha política, sin el aval de ninguna ideología. Octavio Paz ve en la Revolución mexicana un ejemplo sobresaliente y admirable de búsqueda ofuscada pero sincera de una salida a tanto desvarío doctrinal:

"Desnuda de doctrinas previas, ajenas o propias, la Revolución será una explosión de la realidad y una búsqueda a tientas de la doctrina universal que la justifique y la inserte en la Historia de América y en la del mundo.» ${ }^{22}$

El sino de las teorías políticas universalistas en el siglo XIX ha sido particularizarse en sentido perverso y falaz al ser puestas en práctica. Las revoluciones socialistas iniciadas a principios del siglo XX no han tenido mejor suerte. Desengañado del liberalismo y del socialismo, el joven Paz prefiere invertir el sentido del proceso: de lo particular a lo universal, de la práctica a la teoría. Hay cierto adanismo político en su opción, una creencia tal vez ingenua en que la pureza de intenciones y el activismo impremeditado pueden suplir con ventaja a la reflexión y el cálculo. Tal vez influyera algo en esta actitud el contacto con los allegados a Trotsky en su exilio mexicano. El riesgo de derivar hacia posiciones anarquistas tampoco es desdeñable. No obstante, Paz siempre ha tenido resortes intelectuales para evitar caer en el esquematismo fácil. Nada más alejado de él que el utopismo político; su inserción en el tiempo de la historia es muy sólida, ya que su aprecio de la tradición lo une al pasado, su realismo le hace tener los pies bien asentados en el presente y su posibilismo le da una singular clarividencia para anticipar el futuro. Y además esa visión dialéctica no reduccionista a la que ya me he referido le previene contra el riesgo de desatender ningún agente social significativo. La historia está indisolublemente unida al conflicto y Paz no cree que sea bueno eliminar los factores que pugnan dentro de ella, ni someter unos a otros: lo aconsejable es encontrar una fórmula que conjugue dinamismo y equilibrio, que encauce creativa y no destructivamente el despliegue de esos antagonismos:

« El problema era el mismo que se planteaba a escritores y artistas: encontrar una solución orgánica, total, que no sacrificara las particularidades de nuestro ser a la universalidad del sistema, como había ocurrido con el liberalismo, y que tampoco redujera nuestra participación a la actitud pasiva, extática del creyente o del imitador. ${ }^{23}$

Por consiguiente, no se trata ni de encerrarse en los propios particularismos "ni de extrañarse en una universalidad abstracta. No hay que fiarlo todo a la iniciativa privada ni tampoco descansar en el colectivismo puro. Se debe evitar atrincherarse en la tradición, así como mirar sólo hacia el futuro... Dema-

22 O. Paz, El laberinto..., p. 127.

${ }^{23}$ O. Paz, El laberinto..., p. 140. 
siadas exigencias, en suma, para la imaginación que trata de forjar un nuevo proyecto político. Paz acaba transigiendo con la prosaica realidad que ha surgido de la Revolución mexicana, con el sistema de economía mixta puesto en marcha por los presidentes del Partido Revolucionario Institucional, lo cual degrada las altas miras que habían sido establecidas hasta la mediocridad del eclecticismo. El Estado, mediante su intervención es a su juicio el único factor dinamizante de la economía y la garantía más segura del progreso de los países en desarrollo: «Esta "aceleración" se llama: intervención del Estado, dirección -así sea parcial- de la economía. Gracias a esta política nuestra evolución es de las más rápidas y constantes en América. ${ }^{24}$ Los resabios de la apenas superada etapa de adhesión al socialismo se reflejan en el canto a la economía dirigida y a la racionalidad de su gestión económica. El desengaño no se ha producido, por tanto, de la mano de la ciencia económica, sino de la irrenunciable exigencia de libertad: "Nadie duda de que el "socialismo" totalitario puede transformar la economía de un país: es más dudoso que logre liberar al hombre. Y esto último es lo que nos interesa y lo único que puede justificar una revolución..$^{25}$

Cuando escribió El laberinto de la soledad Paz había entrado al servicio del ministerio mexicano de asuntos exteriores, pero no creo que ello lo haga necesariamente sospechoso de falta de independencia al dictaminar sobre el sistema político de su patria. La valoración positiva, que no entusiasta, de la gestión de los gobiernos salidos de la Revolución entra perfectamente dentro de la lógica de su ideario, tal como lo he interpretado aquí, y no veo que haya que exigirle otra cosa. En todo caso es el aspecto menos perspicaz de este brillante ensayo de filosofía de la historia y de la política. Mayor reconocimiento merece la que tal vez sea su tesis central:

"Por primera vez, México no tiene a su disposición un conjunto de ideas universales que justifiquen nuestra situación. Europa, ese almacén de ideas hechas, vive ahora como nosotros: al día. En sentido estricto, el mundo moderno no tiene ya ideas. Por tal razón el mexicano se sitúa ante su realidad como todos los hombres modernos: a solas. En esta desnudez encontrará su verdadera universalidad, que ayer fue mera adaptación del pensamiento europeo.» ${ }^{26}$

No poseer capital es una ventaja cuando se produce la ruina general de los capitalistas: ya se está acostumbrado a salir adelante sin medios, y quizá en la nueva situación de igualdad quepa aprovechar mejor que otros las oportunidades para prosperar. El sucursalismo de México desde el punto de vista cultural y político le obligó en el pasado a aplicar soluciones que no se avenían bien con su idiosincrasia y que ni siquiera eran las más avanzadas del momento. Ante la ruina universal acarreada por la Segunda guerra mundial, todos los

${ }^{24}$ O. Paz, El laberinto..., p. 162.

${ }^{25}$ O. Paz, El laberinto..., p. 165.

${ }^{26}$ O. Paz, El laberinto..., p. 153. 
hombres, todas las sociedades, han recuperado la situación originaria de soledad e indigencia. El joven, el patriota, el intelectual y el poeta confluyen en Octavio Paz para mirar sin complejos y con esperanza hacia adelante. Por otro lado, el crepúsculo de las ideologías que ha tenido ocasión de comprobar por experiencia propia o de sus más próximos ancestros, despeja el panorama de mediaciones y aproxima los dos polos sobre los que pivota el eje de la historia: particularismo y universalidad, a cuyo encuentro sale Paz y en cuya búsqueda recorrerá el mundo durante los decenios siguientes. Largos años pasados en Europa y Asia, la prosecución de la experimentación poética, el estudio de la cultura de la India y el Japón, la investigación de los hitos de la literatura y el arte de Occidente y de México, van dando continuidad a esta búsqueda. Pero, por lo que respecta a la política y el desarrollo social, su puesto de observación privilegiado le permite observar en directo la inexactitud de su diagnóstico: los países de socialismo totalitario son incapaces de gestionar racional y eficazmente la economía, pero los del tercer mundo tampoco saben aprovechar las oportunidades de la postguerra y van quedando atrás en la carrera del desarrollo con respecto a los que intervinieron en el conflicto. Países que, como México, parecían estar bien colocados de cara a una emancipación definitiva ven naufragar sus esperanzas y caen en el marasmo cuando no en el desorden y el caos. En su momento, Octavio Paz analizará las causas de esta evolución imprevista. Y ese momento llega con los acontecimientos de 1968.

Un texto autobiográfico relata con detalle cómo vivió los acontecimientos del mayo francés. En la cumbre de su carrera profesional y gozando de un prestigio internacional reconocido como escritor, tenía todas las razones del mundo para considerarse un hombre del sistema. De hecho, tal era la fama que tenía entre los radicales. Mas he aquí que las noticias de una nueva e imprevista revolución llegan hasta él. Y entonces, su corazón vibra de nuevo como cuando era un universitario insurrecto contra el orden burgués del planeta:

"Durante esas semanas sentí que mis esperanzas juveniles renacían: si los obreros y los estudiantes se unían, asistiríamos a la primera y verdadera revolución socialista. Tal vez Marx no se había equivocado; la revolución estallaría en un país avanzado, con un proletariado maduro y educado en las tradiciones democráticas. Esta revolución se extendería a todo el mundo desarrollado, acabaría con el capitalismo y también con los regímenes totalitarios que habian usurpado el nombre del socialismo en Rusia, China, Cuba y otros países. $Y$ una novedad no prevista por Marx: esa revolución sería asimismo el comienzo de una profunda mutación de las conciencias. La poesía, heredera de las grandes tradiciones espirituales de Occidente, entraba en acción. Era la realización, al fin, de los sueños de los románticos del siglo XIX y de los surrealistas del siglo $\mathrm{XX} .{ }^{27}$

¿Una recaída pasajera en la fiebre izquierdista que había inflamado su juventud? La marcha de los acontecimientos no tardaron en desengañarle de

${ }^{27}$ O. Paz, Vislumbres de la India, p. 213. 
las ilusiones que pudo haber abrigado sobre la apoteosis de un socialismo libre y humanista. Los obreros se negaron a secundar a los estudiantes y todas las sociedades del mundo se detuvieron al borde del abismo que se abría ante el orden establecido: las de Occidente, por la fuerza de las urnas; las de Oriente, por la de los tanques del pacto de Varsovia; las del Tercer Mundo, por la de los fusiles de los soldados que dispararon contra la multitud en la plaza de Tlatelolco. Octavio Paz tuvo que reconocer la inviabilidad de los movimientos subversivos desatados en todas las latitudes. Pero no dejó de solidarizarse con ellos: su dimisión como embajador, el escándalo que produjo, su abierta toma de postura contra la represión ejercida en México, la etapa subsiguiente de exilio encubierto y la asunción consciente del papel de intelectual crítico, certifican la seriedad de su determinación. Tras la crisis de 1939, la del 68 propicia el segundo punto de inflexión en la evolución de su perfil ideológico, al menos externamente considerado. Un par de años más tarde haría balance de lo ocurrido y por ocurrir en el ensayo Posdata (1970). No se refiere allí a sus propias vivencias: la trascendencia histórica de los recientes acontecimientos polarizan todo el interés. Transmite la sensación de que la Historia se está moviendo literalmente ante la distraída mirada de los contemporáneos y que importa realizar un esfuerzo supremo para interpretar con lucidez los signos de los tiempos. Y lo menos que se puede decir del análisis de Paz es que es, efectivamente, lúcido. Lúcido y también desengañado: constata ante todo el agotamiento de los modelos de acción política que han estado vigentes hasta la fecha. Así pues, parte de una visión pesimista del presente, aunque atemperada por la esperanza de nuevas alternativas esbozadas sólo a medias:

"Los modelos de desarrollo que nos ofrecen el Oeste y el Este son compendios de horrores: ¿podremos nosotros inventar modelos más humanos y que correspondan a lo que somos? ${ }^{28}$

Cuando alguien se desengaña de todo, corre el riesgo de perder la capacidad de discriminar: puesto que nada vale, todo es igualmente malo, nada promete una salida, una vía de escape... No es éste el caso de Octavio Paz, porque se encuentra demasiado interesado en la novedad intrínseca de los recientes acontecimientos, que desafían los esfuerzos hermenéuticos de la politología ortodoxa y suponen la definitiva superación por los hechos del esquema lineal de la dialéctica marxista: "Es claro que no estamos ante un recrudecimiento de la lucha de clases sino ante una revuelta de esos sectores que, de un modo permanente o transitorio, la sociedad tecnológica ha colocado al margen. $\gg^{29}$ A la polarización izquierda-derecha (la lucha de clases) hay que superponer la tensión norte-sur (países ricos y pobres) e incluso la generalización topológica del conflicto entre el centro y la periferia (dialéctica integración- marginalidad),

${ }^{28}$ O. Paz, Posdata, p. 13.

${ }^{29}$ O. Paz, Posdata, p. 22. 
si queremos obtener la cartografía completa y representativa de la conflictividad social a escala planetaria. A fin de cuentas, la clase obrera de los países industrializados se ha convertido en una casta privilegiada más cuya preocupación principal es conservar e incrementar sus ventajas en perjuicio de los desheredados de la fortuna que los antiguos proletarios han empezado a compartir con los poderosos. Más aún: ni siquiera es legítimo seguir planteando el problema de las causas de la pobreza y marginación en términos de robo y explotación. La teoría de la dependencia había superpuesto al modelo de los trabajadores explotados por los capitalistas otro en el que los países ricos expropian las materias primas de los países pobres. Es evidente que ambos fenómenos se han dado, se dan y se seguirán dando, pero con aguda visión Paz se da cuenta de la falacia que se comete cuando se elevan a causas necesarias y determinantes de la abundancia de los prósperos:

"El imperialismo puede desaparecer mañana, ya sea por un cambio de régimen en los Estados Unidos o, más probablemente, porque la técnica y la ciencia acabarán por descubrir sustitutos para nuestras materias primas y porque las economias de los paises desarrollados serán progresivamente autosuficientes. Tal vez en un futuro no demasiado lejano los países adelantados ni siquiera esquilmarán a los subdesarrollados: los abandonarán a su miseria y a sus convulsiones. $x^{30}$

Treinta años después de haber sido escritas, nadie puede negar la clarividencia y visión profética de estas palabras. Rotas las amarras de la ortodoxia analítica, Paz arremete contra los más queridos ídolos de los revolucionarios de viejo cuño: por ejemplo, invierte la relación infraestructura/superestructura y convierte al Estado no en reflejo de las relaciones de producción de una sociedad, sino en entidad autónoma y en cierto modo generadora de su propia infraestructura: "...el Estado no es tanto la expresión de la clase dominante, al menos en su origen, sino que ésta es el resultado de la acción del Estado.»31 En realidad, hacer de las relaciones de producción el único motor de la historia y la única variable decisiva de la dinámica social es demasiado simplista; a esa dialéctica unidimensional Paz opone una dialéctica pluridimensional, en la que los contrarios no se limitan a representar momentos necesarios de un proceso que como tales van quedando atrás a medida que éste avanza, sino que constituyen factores no prescindibles ni superables, cuya presencia y permanencia enriquece y asegura la vitalidad de las sociedades que saben darles cabida dentro de sí. En cierto modo lo que ocurre es que Paz está descubriendo la enorme complejidad de la política y al mismo tiempo la ingenua simplicidad de los esquemas de acción de los políticos e ideólogos. En la política se mezclan intimamente las instancias naturales y las éticas. Para ser buen político es

\footnotetext{
${ }^{30}$ O. Paz, Posdata, pp. 61-62.

${ }^{31}$ O. Paz, Posdata, p. 67. En otro lugar afirma: «No solamente ha ocurrido exactamente lo contrario [de su pronosticada disminución o desaparición] sino que ahora empezamos a sospechar que el Estado es una realidad relativamente autónoma.» Ibid., p. 97.
} 
imprescindible ser honesto y también dominar los resortes y las inercias de la maquinaria social. Tan nefasto es prescindir del lado ético (tecnocracia) como ignorar la dosis de necesidad natural que encierra (voluntarismo político). La receta de Octavio Paz tras largos años de experiencias, ilusiones y fracasos es que hay que reducir la axiología de la acción política a un único principio categórico: la lucha por la emancipación, por la libertad efectiva y no meramente abstracta de los ciudadanos, la apuesta, en suma, por la democracia:

"No se puede sacrificar el pensamiento crítico en las aras del desarrollo económico acelerado, la idea revolucionaria, el prestigio y la infalibilidad de un jefe o de cualquier otro espejismo análogo. Las experiencias de Rusia y México son concluyentes: sin democracia, el desarrollo económico carece de sentido.... ${ }^{32}$

Llegado a la plena madurez, Octavio Paz se presenta como un demócrata sin apellidos, como un liberal en el más depurado y noble de los sentidos. No equivale esto a una opción por el capitalismo. Sin llegar a las condenas del "capitalismo salvaje» en las que vuelcan su resentimiento muchos exrevolucionarios reconvertidos en críticos del sistema triunfante, Paz no se hace ilusiones sobre las ponderadas virtudes de la "mano invisible" para promover el bienestar social, además de la riqueza material. Sin duda se ha desengañado de las ventajas que en diversos momento de su vida atribuyó al socialismo. Pero una política que se limite a procurar la libre aplicación de las leyes del mercado tampoco es para él la panacea, ni mucho menos. Desconocer los enormes desequilibrios y carencias que padece el "primer mundo» sólo se explica por una ceguera interesada o por una insensatez rayana en la locura:

"Olvidemos por un momento los crímenes y las estupideces que se han cometido en nombre del desarrollo, de la Rusia comunista a la India socialista y de la Argentina peronista al Egipto nasserista, y veamos lo que pasa en los Estados Unidos y la Europa occidental: la destrucción del equilibrio ecológico, la contaminación de los espíritus y de los pulmones, las aglomeracio- nes y los miasmas en los suburbios infernales, los estragos psíquicos en la adolescencia, el abandono de los viejos, la erosión de la sensibilidad, la corrupción de la imaginación, el envillecimiento de Eros, la acumulación de los desperdicios, la explosión de odio.... ${ }^{33}$

Un liberal clásico podría contraargumentar que los males del mundo liberal se deben, por una parte, a que tampoco en este ámbito se aplican en su integridad los principios de la economía libre y, en segundo lugar, a que este sistema no promete arreglar todos los problemas del hombre, sino organizar del modo más racional y eficaz posible el tejido de relaciones sociales, dejando que los individuos intenten resolver en la esfera privada los que les atañen en cuanto individuos. Si las personas deciden libremente ser infelices, ni los políticos

\footnotetext{
32. O. Paz, Posdata, p. 30.

${ }^{33}$ O. Paz, Posdata, pp. 74-75.
} 
ni los magistrados están facultados para remediarlo. A esto habría que decir que, decididamente, Octavio $\mathrm{Paz}$ no es un liberal clásico, aunque al término de su evolución coincida con ellos en que suele ser bastante nefasto mezclar indiscriminadamente las consideraciones éticas con la economía y la ingeniería social: " La política, además, es una práctica; no sé si sea realmente una ciencia y tampoco estoy muy seguro de que sea un arte. Más bien es una técnica.» ${ }^{34}$ El principal error cometido por la izquierda en el siglo XX radica precisamente en creer que la bondad del sistema que propugnaban estaba garantizado estatutariamente: la corrupción y la injusticia no podrían presentarse en una sociedad socialista ni tendrían relevancia en un proceso revolucionario a ella encaminado. Es como si la sociedad expropiase a los individuos - incluso a los funcionarios y jerarcas encargados de administrar el orden revolucionario- la responsabilidad ética y la necesidad de esforzarse día a día por el logro de la justicia: el sistema revolucionario, la sabiduria de sus estructuras les ahorrarían ese trabajo; a ellos les bastaría con evitar convertirse en contrarrevolucionarios. Pero no es así: la responsabilidad ética y política es personal e intrasferible; no hay sistema que no podamos hacer malo, incluso sin traicionarlo en absoluto; no hay revolución que no puede ser pervertida desde dentro, transformando el sueño en pesadilla:

" En 1937 la amenaza eran Hitler y sus aliados. Hicimos bien en oponernos. Además, había la gran esperanza encendida por la Revolución de Octubre. Ahora sabemos que ese resplandor, que a nosotros nos parecía el de la aurora, era el de una pila sangrienta.» ${ }^{35}$

Ahora bien, aunque la constitución y leyes de un país no puedan reemplazar la buena voluntad de los encargados de regirlo, esto no significa que todo dependa de las virtudes personales de los políticos. Como advierte el viejo refrán castellano, « el infierno está tapizado de buenas intenciones». La política, acaba de decirnos Paz, es una técnica, y la utilidad de toda técnica es potenciar los efectos favorables de la acción humana y amortiguar los negativos. En política habrá que optar entonces por los ordenamientos que faciliten la remoción de las disposiciones erróneas y de las autoridades nefastas, y que en cambio refuercen los buenos efectos de las legislaciones y agentes idóneos:

"Pero las mejores leyes del mundo se convierten en letra muerta si el gobernante es un déspota, un hombre que domina a los demás porque es incapaz de dominarse a sí mismo. Repito: una política secular realista combina la modernidad democrática con la vieja y tradicional virtud de la prudencia. $\gg^{36}$

La receta es saludable pero vaga. ¿Cómo asegurarnos de la calidad de los ingredientes y del acierto en las proporciones de la mezcla? Es aquí donde

${ }^{34}$ O. Paz, Itinerario, p. 237.

${ }^{35}$ Entrevista con O. Paz en Proceso (1977), citada por Vizcaino, Biografia..., pp. 153-154.

${ }^{36}$ O. Paz, Vislumbres de la India, p. 153. 
la palabra «democracia» se convierte en la clave del pensamiento político del Paz maduro. La democracia es la condición de posibilidad del ejercicio libre de la crítica a los poderes establecidos. Arrepentido del «colaboracionismo» político con el gobierno, nuestro hombre asume que la crítica es la función social propia del intelectual y del artista. ${ }^{37}$ No se trata de un mero adorno del sistema político, sino de un momento estructuralmente necesario, sobre todo cuando se inicia un proceso de renovación y cambio: «toda revolución sin pensamiento crítico, sin libertad para contradecir al poderoso y sin la posibilidad de sustituir pacíficamente a un gobernante por otro, es una revolución que se derrota a sí misma. ${ }^{38}$ En este sentido, crítica y democracia son conceptos entrelazados. Negar o limitar una de ellas es lo mismo que negar o limitar la otra. Por eso son sospechosas las ideologías que instrumentalizan la crítica o la restringen a unas determinadas coordenadas: "Para Marx la crítica del cielo era el comienzo de la crítica de este mundo. No se equivocaba. Hay que añadir que ambas críticas son inseparables en la democracia.» ${ }^{39}$

La crítica, claro está, ha de ser ejercida en nombre de una racionalidad, pues con ella se apela al consenso de interlocutores avisados e imparciales. En este punto, la racionalidad crítica se alía con la racionalidad económica que constituye el punto fuerte del liberalismo económico. Aunque sea a última hora, los efectos de la "mano invisible» parecen coincidir con las exigencias de la ética: "La relación se ha invertido: primero fue imperativo el progreso económico; ahora, para que éste continúe, es igualmente imperativo el desarrollo social: la justicia. $\gg^{40}$ Es como si la buena marcha de la economía requiriera la desaparición de las lacras sociales pero sólo a partir de un momento determinado: el desarrollo podría iniciarse a espaldas de la justicia - $y$, dicho sea de paso, también en contra de los principios del liberalismo económico- , pero para ser culminado no habría otro camino que el que dictan las leyes del mercado y los requisitos del bienestar social. Aquí estaría precisamente la justificación ética del liberalismo: justicia y democracia como condiciones y también consecuencias indirectas de la racionalidad económica. Según esto, sólo una sociedad libre y justa puede franquear definitivamente el umbral del subdesarrollo. Las naciones de Occidente, en la medida que pervive en su seno la injusticia, no lo han logrado todavía. Todo ello no significa que deban fusionarse la democracia y el liberalismo económico, ni siquiera en los estadios avanzados del desarrollo, ya que:

"Por supuesto, la democracia no es una panacea que cure todas las dolencias y que imponga de manera automática la justicia social. No es un método para acelerar

\footnotetext{
37 Crítica no equivale a oposición sistemática: $O$. Paz apoyó por ejemplo los esfuerzos del presidente de La Madrid por disminuir el sector público mexicano a nivel económico, político y social. Véase Vizcaino, Biografia..., p. 181

38 O. Paz, Posdata, p. 100.

${ }^{39}$ O. Paz, Vislumbres de la India, p. 194.

${ }^{40}$ O. Paz, Posdata, p. 72.
} 
el proceso económico; es un medio para evitar que ese progreso se realice a expensas de la mayoría.» ${ }^{41}$

De esta forma se cierra el ciclo de una evolución del socialismo al liberalismo sin que sea preciso suponer la existencia de rupturas y quiebras profundas. En el anciano demócrata que hace balance de su vida en Itinerario (1993), siguen siendo reconocibles los rasgos principales del joven revolucionario: la misma aspiración a la justicia, el mismo esfuerzo de lucidez crítica, la misma decisión de no sacrificar la realidad por la utopía, el mismo criterio de no subordinar la complejidad de la historia a la bellas simetrías de las teorías que tratan de desvelar sus secretos. Si acaso, se ha hecho más consciente de las dificultades, menos confiado en la validez de los «atajos», más prudente a la hora de actuar, menos perezoso a la hora de profundizar en los misterios y paradojas del individuo y de la vida social. Ha aprendido a cumplir con el precepto de dar al César lo que es del César y por eso acata las inercias y dinamismos socio- económicos que es inútil pretender remover con consignas ideológicas e imperativos morales. Pero ello no le impide perseverar en la idea de que unas y otros tienen también un lugar en la praxis política. $Y$, superados los errores históricos de los totalitarismos de cualquier índole y condición, hay que dar prioridad a la búsqueda de la ubicación correcta de la dimensión ética. El diagnóstico de los males de las civilizaciones más avanzadas es el primer paso a dar para ello. Octavio Paz lo da con decisión y deja claro que para él la democracia no es de ningún modo la solución definitiva sino una ayuda para buscar respuestas nuevas a problemas de siempre: lejos de constituir un absoluto, o tan siquiera un proyecto sobre el futuro, se queda en método de la conciencia civilizada. ${ }^{42}$

El padecimiento más oneroso del mundo de hoy es a su juicio la desintegración, la incapacidad para impedir que las tensiones inherentes a la vida social vayan desgajando del núcleo central sectores marginales cada vez mayores. El caso de México es singularmente representativo, porque el país está escindido en dos: uno desarrollado y otro marginal, que acabará con el primero si éste no aprende a integrarlo. ${ }^{43}$ Los dos Méxicos representan simbólicamente los dos mundos (ahora que el "segundo mundo» ha desparecido) segregados y opuestos en todas las escalas de la geografia (hay marginalidad en el planeta, en cada continente, cada país, cada ciudad y cada barrio). Pero, una vez más, de nada vale pintar con los más negros colores los males presentes. Paz rechaza con gesto decidido los fúnebres lamentos y las condenas monocordes de quienes "no han conseguido digerir su propio fracaso y disfrazan la frustración que sienten con los tópicos al uso:

\footnotetext{
41 O. Paz, Vislumbres de la India, p. 155.

42 Véase O. Paz, Itinerario, p. 125.

43 Véase O. Paz, Posdata, p. 93.
} 
"Las ideologías vencidas regresan a nuestras mesas de debates bajo la máscara de la ecología. Muchos de los discursos pronunciados en Río de Janeiro me parecieron abusos de lenguaje y me recordaron, unos, la retórica populista tercermundista y, otros, las diatribas y las jeremiadas de los reaccionarios. En busca de chivos expiatorios, unos culpan al imperialismo y otros a la ciencia. Hay que defender a la justa causa ecológica de la demagogia política de algunos de sus voceros.» ${ }^{44}$

La crítica es para Paz tan sólo el primer peldaño en la búsqueda de rumbo. Si la humanidad actual está cada vez más escindida, en sí misma y con respecto al mundo natural, ¿dónde está la raíz del problema y cómo atajarlo? No es tan difícil decirlo: en las democracias tienden a disolverse los lazos que unen a los ciudadanos entre sí y con sus antepasados; el igualitarismo coexiste con el individualismo: ${ }^{45}$ En nuestro mundo la conformidad y la pasividad conviven con el egoísmo más despiadado y el individualismo más obtuso. ${ }^{46}$ ¿Por qué? Tal vez por el carácter meramente funcional, formal, que la palabra libertad tiene en el liberalismo político y económico vigente. Algo parecido ocurre con la democracia. Pero no se puede hacer una democracia sin ciudadanos responsables, ni una economía de mercado sin agentes económicos libres en el más pleno - esto es, lleno de contenido- sentido. Esta denuncia ya había sido formulada por los fundadores del materialismo dialéctico contra el liberalismo burgués, y recogida por Paz en El laberinto de la soledad: « La libertad y la igualdad eran, y son, conceptos vacios, ideas sin más contenido histórico que el que le prestan las relaciones sociales, como ha mostrado Marx. Y ya se sabe en qué se convirtió esa igualdad abstracta y cuál fue el significado de esa libertad vacía. ${ }^{47}$ Con el paso del tiempo no se desdice de ella, pero, a diferencia de Marx, ni al principio ni al final significa para él una descalificación de la idea, sino una llamada urgente a la reparación: es imperioso lograr una cultura de la libertad, una doctrina que nos convenza a todos de que, en vez de dejarnos llevar por un arbitrio vacío o por las pulsiones inmediatas que nos asaltan, hemos de construir nuestro destino y nosotros mismos con él. Porque, cuando la virtud flaquea, las repúblicas perecen: «Nuestro hedonismo no es una filosofía del placer sino una abdicáción del albedrío y habría escandalizado, por igual, al dulce Epicuro y al frenético Donatien de Sade. ${ }^{48}$

No abdicar del albedrio equivale a no dejar que su lugar sea ocupado por el azar en ninguna de sus muchas e igualmente gratuitas formas. Significa reintroducir con plenitud de derechos la instancia moral, y teñir con el esforzado tinte de la ética nuestro caminar por el tiempo. A fin de cuentas, la historia se convierte de nuevo en la epopeya de la lucha entre el bien y el mal:

\footnotetext{
${ }^{44}$ O. Paz, Itinerario, p. 154.

${ }^{45}$ Véase O. Paz, Vislumbres de la India, pp. 76-77.

${ }^{46}$ O. Paz, Itinerario, p. 160.

${ }^{47}$ O. Paz, El laberinto..., p. 116.

${ }^{48}$ O. Paz, Itinerario, p. 132.
} 
"El mal es humano, exclusivamente humano. Pero no todo es maldad en el hombre. El nido del mal está en su conciencia, en su libertad. En ella está también el remedio, la respuesta contra el mal. Ésta es la única lección que yo puedo deducir de este largo y sinuoso itinerario: luchar contra el mal es luchar contra nosotros mismos. Y ése es el sentido de la historia. ${ }^{49}$

Terminaré con una reflexión personal. He seguido con interés y sin fatiga hasta este punto el peregrinaje de Octavio Paz a la búsqueda de su ideario político. Me temo que tendría que dejarlo solo a partir de este momento, porque no me convence la peculiar metafísica del presente y de la finitud en que trata de asentar su filosofia de la libertad. Pero no es el momento más apropiado para discutir este dificultoso y crucial punto del pensamiento paziano. Espero que el lector lo encuentre tan interesante como yo y deseo que se anime a dialogar con sus libros para cotejar la fidelidad de mi interpretación y llegar seguramente a conclusiones más ajustadas y sugerentes.

\footnotetext{
${ }^{49}$ O. Paz, Itinerario, p. 140.
} 